\title{
RNA-seq and microarray complement each other in transcriptome profiling
}

\author{
Sunitha Kogenaru, Qing Yan, Yinping Guo and Nian Wang*
}

\begin{abstract}
Background: RNA-seq and microarray are the two popular methods employed for genome-wide transcriptome profiling. Current comparison studies have shown that transcriptome quantified by these two methods correlated well. However, none of them have addressed if they complement each other, considering the strengths and the limitations inherent with them. The pivotal requirement to address this question is the knowledge of a well known data set. In this regard, HrpX regulome from pathogenic bacteria serves as an ideal choice as the target genes of HrpX transcription factor are well studied due to their central role in pathogenicity.

Results: We compared the performance of RNA-seq and microarray in their ability to detect known HrpX target genes by profiling the transcriptome from the wild-type and the hrpX mutant strains of $Y$-Proteobacterium Xanthomonas citri subsp. citri. Our comparative analysis indicated that gene expression levels quantified by RNA-seq and microarray well-correlated both at absolute as well as relative levels (Spearman correlation-coefficient, $r_{s}>0.76$ ). Further, the expression levels quantified by RNA-seq and microarray for the significantly differentially expressed genes (DEGs) also well-correlated with qRT-PCR based quantification ( $r_{s}=0.58$ to 0.94$)$. Finally, in addition to the 55 newly identified DEGs, $72 \%$ of the already known HrpX target genes were detected by both RNA-seq and microarray, while, the remaining $28 \%$ could only be detected by either one of the methods.

Conclusions: This study has significantly advanced our understanding of the regulome of the critical transcriptional factor HrpX. RNA-seq and microarray together provide a more comprehensive picture of HrpX regulome by uniquely identifying new DEGs. Our study demonstrated that RNA-seq and microarray complement each other in transcriptome profiling.
\end{abstract}

Keywords: RNA-seq, Microarray, Transcriptome profiling, Pathogenic bacteria, Virulence, Type 3 secretion system, Effectors, HrpX, Xanthomonas, Citrus canker disease

\section{Background}

Transcriptome of an organism represents the entire repertoire of transcripts encoded by the genes as a phenotypic response to the condition in which they exist. The sheer ability to simultaneously quantify the expression levels for a vast number of genes has revolutionized the biomedical research, facilitating the analysis of global gene expression patterns at the genome-wide scale [1]. In the past decade, there has been a tremendous progress in the development of methods to deduce and quantify the gene expression levels at the whole transcriptome level [1]. Among the several transcriptome

\footnotetext{
* Correspondence: nianwang@ufl.edu

Citrus Research and Education Center, Department of Microbiology and Cell Science, Institute of Food and Agricultural Sciences, University of Florida, 700 Experiment Station Road, Lake Alfred 33850, USA
}

profiling methods, RNA-seq and DNA microarray stand out as the two widely used genome-wide gene expression quantification methods [1-17].

RNA-seq method involves the conversion of isolated transcripts into the complementary DNA (cDNA), which is then directly sequenced in a massively parallel deepsequencing-based approach [18]. By mapping the resulting short sequencing reads onto the reference genome, the expression levels of genes relative to the condition of interest or absolute levels can be quantified $[9,11]$. This method has been implemented in different platforms like Illumina's Genome Analyzer, Roche 454 Genome Sequence, and Applied Biosystems' SOLiD [4]. On the other hand, microarray is based on the hybridization of specimen target strands onto the immobilized complementary probe strands. For example, in a two-color microarray, transcripts 
extracted from different conditions are labeled with distinct fluorescent dyes while being converted to cDNA. These labeled samples are then hybridized to the immobilized complementary probe strands in an array representing the genes. By measuring the light intensity of the distinct fluorescent dyes, the relative abundance of each transcript in the two different conditions can be measured $[8,12,13,17,19,20]$. Affymetrix and Agilent are the two prevalent platforms in microarray technology $[2,14]$.

Even though, initially microarray has been instrumental in whole transcriptome analysis, currently RNA-seq is becoming a preferred method of choice, since it is considered to effectively surmount the limitations of microarray [1,21-23]. RNA-seq technology, unlike microarray, does not depend on the prerequisite knowledge of the reference transcriptome [24]. Further, RNA-seq data contains very low background signal, a higher dynamic range of expression levels, and also relatively small amount of total RNA required for quantification, when compared to microarray [1,23]. Despite these advantages, the efficiency of RNA-seq is marred with the problem of overwhelming amount of ribosomal RNA (rRNA) in the data, short reads, less base accuracy, and variation of read density along the length of the transcript, posing a challenge for this high-throughput method $[21,25,26]$. However, in spite of their strengths and limitations, RNA-seq and microarray have become the default popular methods of choices for genomewide transcriptome studies [1,2,23].

Currently several studies have been conducted to compare the performance of RNA-seq and microarray in quantifying the expression level of genes, by focusing on various aspects like reproducibility, accuracy, statistical issues, technical and biological variabilities $[1,15,21,27-30]$. The main conclusion from these studies has been that the expression levels quantified by these two methods correlated to a large extent, and overall favored the RNA-seq because of high reproducibility, accuracy, and dynamic range [27,29]. However, none of these comparison studies have addressed if these two methods complement each other in transcriptome profiling given the strengths and limitations associated with them. In order to address this question, we require an already well characterized dataset. The HrpX regulome from Xanthomonas citri subsp. citri (Xcc) serves as an ideal data model in this regard [31-33]. Xcc is a causal agent of citrus canker, one of the serious and destructive diseases in citrus that is resulting in significant losses to citrus industry worldwide [34], while HrpX is a key global transcription factor that regulates the expression of hrp (hypersensitive response and pathogenicity) cluster of genes, which are considered as the major pathogenicity factors $[31,35]$. HrpX contains AraC-type of DNA binding domain, which specifically recognizes the plantinducible promoter (PIP) box (TTCGC-N15-TTCGC) and imperfect PIP box (TTCGC-N8-TTCGT) present in the cis-regulatory regions of hrp gene cluster [36-38]. Since HrpX has a key role in pathogenicity, tremendous progress has been made in cataloguing the target genes of HrpX [39-45]. We therefore assessed the performance of RNA-seq and microarray in their ability to detect known HrpX target genes. We chose Illumina and Agilent as the corresponding platforms for RNA-seq and microarray, as they are the most popular platforms for these technologies $[2,4]$.

\section{Results}

In order to uncover the regulome of HrpX transcription regulator by profiling the wild-type and the hrpX mutant strains transcriptome, we had designed a microarray chip covering the whole genome under Agilent platform in our previous study [33]. Here, we conducted genomewide transcriptome profiling of these two strains by RNA-seq and compared the results to the previously published microarray data, to assess the performance of these two methods. Further, to avoid technical variation associated with RNA isolation, we used the aliquots from the same total RNA samples used for microarray experiments also for RNA-seq.

We obtained 16,431,283, 17,289,220, 18,124,120 sequence reads for the wild-type and 15,084,955, 17,831,920, and $18,115,115$ for the $h r p X$ mutant strain with a median sequence length of 74-base pairs (bp) (Additional file 1: Table S1). Raw reads often have high sequencing errors, especially in the $3^{\prime}$ end where there is a high chance of sequencing errors to occur [46]. We therefore filtered the reads for high quality ones by trimming off the base pairs with low quality score assigned to them during downline processing of RNA-seq. More than $90 \%$ of the reads passed the quality filter, as a result, the median sequence length of quality filtered reads subsequently dropped to 68-bp (Additional file 1: Table S1). We then mapped these high quality trimmed reads on to the Xcc genome. Approximately more than $90 \%$ of the reads could be mapped on to the reference genome, indicating good sequence coverage (Additional file 1: Table S1). Overall $\sim 97 \%$ of the annotated genes had more than one read mapped, while merely $\sim 3 \%$ of the annotated genes had no reads mapped, indicating good sequencing depth. Further, we also observed a difference in the sequence coverage between the chromosome and the two endogenous plasmids of Xcc. Annotated coding genes from the chromosome with a size of 5.18 mega base pairs $(\mathrm{Mb})$ had $98 \%$ sequence coverage, whereas, it was $78 \%$ for plasmid pXAC64 with a size of $0.06 \mathrm{Mb}$, and relatively lower with only $62 \%$ sequence 
coverage for plasmid pXAC33 with a size of $0.03 \mathrm{Mb}$ (Additional file 1: Table S2).

\section{Comparison at absolute levels of expression}

RNA-seq had coverage for 4323 genes with one or more reads mapped, while by microarray 4349 genes were assigned the fluorescence intensity values after the background correction. Among these 4312 genes ( $\sim 99 \%$ of the total genes) were common to both methods, while merely $37(0.8 \%)$ and 11 genes $(0.2 \%)$ were uniquely called by microarray and RNA-seq respectively (Additional file 1: Tables S2 and S3; Additional file 2: Figure FS1). We compared the absolute levels of gene expression in terms of RNA-seq counts and microarray fluorescence intensities for all the listed genes called by both the methods. These two independent measures of transcript abundance associated with each gene for all the biological replicates from the wild-type and the $h r p X$ mutant strains were compared separately. The resulting correlation was mapped as a scatter plot, with an average number of counts from Illumina sequencing against the normalized fluorescence intensities from Agilent arrays for each gene in the wild-type (Figure 1A) as well as in the $h r p X$ mutant (Figure 1B). Absolute levels of gene expression correlated well, when estimated in terms of Spearman's correlation coefficient $\left(\mathrm{r}_{\mathrm{s}}\right)$ with 0.78 ( $\mathrm{p}$-value $<0.0001)$ for the wild-type and 0.80 (p-value $<0.0001$ ) for the $h r p X$ mutant strain. This is in agreement with the previous reports that expression levels measured by microarray and RNA-seq had correlations ranging between 0.62 and 0.8 for prokaryotic and eukaryotic datasets $[18,28,29]$. However, there seems to be little or no correlation for the genes with low level of expression. We further estimated the correlation for the subset of genes with fluorescence intensity values $\leq 100$ assigned by microarray ( $\sim 360$ genes) with the corresponding expression levels determined by RNA-seq. This subset of genes revealed a very poor $r_{s}$ of 0.2 ( $p$-value $\left.<0.0002\right)$ and 0.3 (p-value $<0.0001$ ) for the wild-type and the $h r p X$ mutant strains respectively. Although the expression levels of these genes did not change much according to microarray, RNA-seq reported them to have different expression levels. This may be attributed to the high sensitivity of RNA-seq method.

We further estimated the correlation between all the combinations of biological replicates for the wild-type and the $h r p X$ mutant strains independently. The resulting $r_{s}$ values of these comparisons are represented in the form of heat maps, for the wild-type (Figure 1C) and the $h r p X$ mutant strains (Figure 1D), which provide a global view of these correlations. Overall, on an average the wild-type with $\mathrm{r}_{\mathrm{s}}=0.76$ (p-value $\left.<0.0001\right)$ and the $h r p X$ mutant with $r_{s}=0.78$ (p-value $<0.0001$ ) were observed for the biological replicates from all the correlation combinations. This level of comparison strongly suggested that not only the absolute level of gene expressions
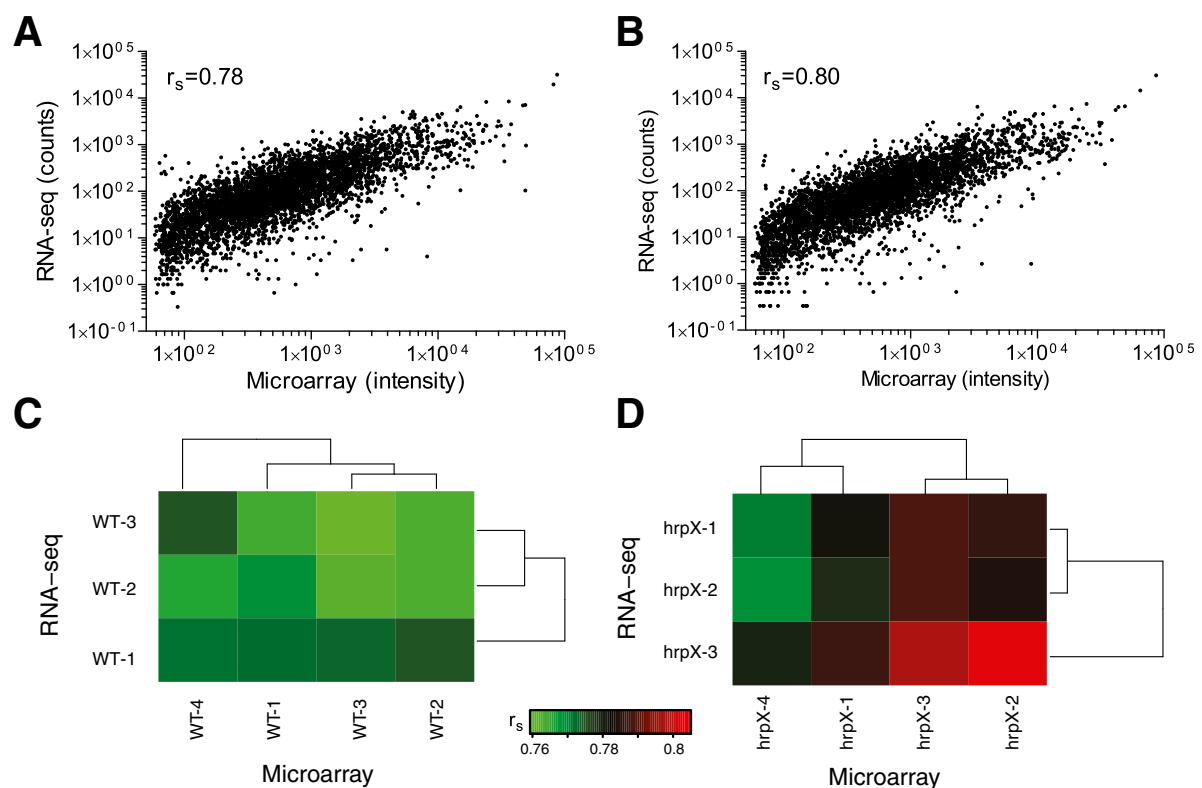

Figure 1 Comparison of absolute levels of gene expression by RNA-seq and microarray. Upper panel shows for the (A) wild-type and (B) hrpX mutant, the correlation between normalized fluorescence intensities of Agilent microarray with the RNA-seq counts from Illumina. Each dot represents the average values for each gene from all the biological replicates. Spearman's correlation coefficient $\left(r_{s}\right)$ is indicated for each comparison. Lower panel shows $r_{s}$ between normalized fluorescence intensities of Agilent microarray with the RNA-seq counts from Illumina for all the combination of biological replicates for the $(\mathbf{C})$ wild-type, and $(\mathbf{D})$ the hrpX mutant. The $r_{s}$ values are plotted in the form of a heat map, where green color represents low $r_{s}$ value, while red represents highest $r_{s}$ value. The dendrogram provides a hierarchical clustering. 
determined by RNA-seq and microarray highly correlated, but were also highly reproducible, in spite of the technical as well as the biological variability associated with the quantifications.

\section{Comparison at relative levels of expression}

We also compared the performance of these two methods at relative level of gene expression. For this purpose, we first computed the relative expression level of genes in terms of fold-change (FC) for the hrpX mutant in relation to the wild-type strain, along with p-values to denote the statistical significance and false discovery rate (FDR), for having a good control over the false positives rate. We compared the relative expression levels for 4312 consensus genes both qualitatively and quantitatively, after transforming the FC values to logarithm base $2\left(\log _{2}\right)$ scale without any statistical cut-off thresholds (Additional file 1: Table S2). For the 2587 ( $60 \%$ of the consensus) genes, the expression levels agreed qualitatively, while 1725 ( 40\%) genes disagreed between the two methods (Figure 2A). At this point, our comparison was exclusively focused on whether the gene of interest is up- or down-regulated based on the sign of the $\log _{2}$ transformed FC values, but not necessarily on the FC magnitude. We further illustrated the quantitative relationship of $\log _{2} \mathrm{FC}$ between RNA-seq and microarray in the form of a scatter plot as shown in Figure 2B. Genes with no change in expression levels in the wildtype and the $h r p X$ mutant strains $(\mathrm{FC}=1)$ clustered around $\log _{2} \mathrm{FC}$ of zero ( $\log _{2}$ of one is zero) in the scatter plot (Figure $2 \mathrm{~B}$ ). The $\mathrm{r}_{\mathrm{s}}$ between the $\log _{2} \mathrm{FCs}$ determined by RNA-seq and microarray was found to be 0.30 ( $\mathrm{p}$-value < 0.0001) (Figure 2B). This lower correlation value indicated that the magnitude of FCs between the two methods differed largely that might be due to the background noise resulting from the many imperfections, which are inherent to the highthroughput technologies $[47,48]$.

The correlation coefficient provides an overall estimate of correlation between the expression levels determined by RNA-seq and microarray methods. However, this does not zoom into the data in a detailed manner. For instance, no information is provided about how much of FC magnitude that actually differs between the two

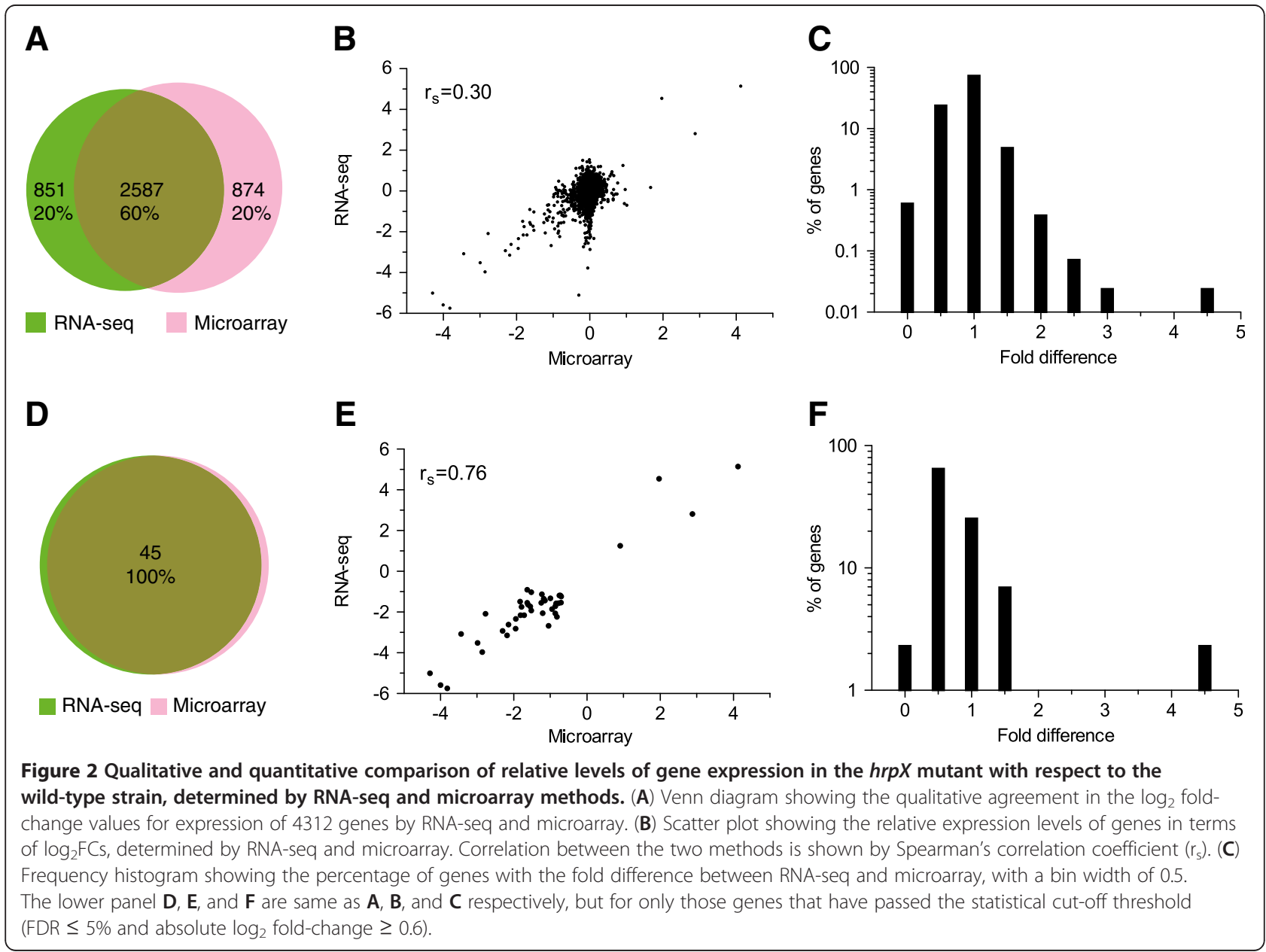


methods for a given gene. In order to get an insight into this aspect, we computed the fraction of genes deviating in their FC magnitude values by dividing the FC magnitude value determined by RNA-seq with that of microarray (Figure 2C). Here, the fold difference of one represents the fraction of genes that are determined to have a FC magnitude of \pm 0.5 (bin width) by both RNAseq and microarray methods. When we plotted this frequency as a histogram for the whole 4312 consensus genes, more than $75 \%$ of genes were found to have FC magnitude values \pm 0.5 by RNA-seq and microarray methods. Since it is a relative expression comparison, genes whose expression values did not change much in the wild-type and the $h r p X$ mutant strains, tend to have $\mathrm{FC}$ values $=1$. Subsequently, it is more sensible to consider only differentially expressed set of genes for further comparisons.

We therefore applied FDR $\leq 0.05$ (5\%) in conjunction with FC (absolute $\log _{2} \mathrm{FC} \geq 0.6$ ) to filter the whole data set. In total, 87 (2\%) genes from RNA-seq and 64 (1.5\%) from microarray qualified at this cut-off threshold from the 4312 consensus genes (Additional file 1: Table S4). Together, 106 genes satisfied our selection criterion from both the methods (Additional file 1: Table S4). Among them $84(79.2 \%)$ genes were up-regulated, while 22 (20.8\%) genes were found to be down-regulated. Further, $45(\sim 42.45 \%)$ genes were common between both the methods, whereas, $42(39.63 \%)$ and 19 ( 17.92\%) genes were uniquely detected by RNA-seq and microarray respectively (Additional file 1: Table S4; Additional file 2: Figure FS2). We further compared the FC values of the 45 consensus genes both qualitatively and quantitatively. These genes qualitatively agreed $100 \%$ by having the same trend of $\log _{2}$ transformed FC values by both RNAseq and microarray (Figure 2D). Likewise the quantitative comparison was performed by estimating the correlation between the magnitude of $\log _{2} \mathrm{FC}$ determined by RNA-seq and microarray for the 45 consensus genes as shown in Figure 2E. The magnitude of FC values between the two methods were found to be well correlated $\left(\mathrm{r}_{\mathrm{s}}=0.76\right.$, $\mathrm{p}$-value $\left.<0.0001\right)$, indicating that the same trend of variation was observed in FC values between the two methods without any dispersion. Thereby, the magnitude of FC values determined by RNA-seq and microarray agreed to a large extent for the 45 consensus genes. In order to further pinpoint the deviation in the FC magnitude quantified by the two methods, we plotted the differences in the FC values determined by RNAseq with respect to microarray, and the percentage of genes with that difference for the 45 consensus genes (Figure 2F). Majority of the genes ( 98\%) were found to have a magnitude of $\mathrm{FC}$ within the range of $\leq 1.5$, while for the remaining $2 \%$ of the genes, it was 4.7-times higher in RNA-seq than the microarray based quantification. Based on these comparisons, we concluded that the relative gene expression levels quantified by RNA-seq and microarray were consistent to a large extent for the statistically differentially expressed set of consensus genes.

\section{Comparison with qRT-PCR}

Traditionally, quantitative Reverse Transcription PCR (qRT-PCR) is used to validate the gene expression levels quantified by high-throughput technologies like RNAseq and microarray [49]. Therefore, we compared the relative expression levels quantified by RNA-seq and microarray by qRT-PCR for a subset of 43 (40.6\%) genes (Additional file 1: Table S5) that were randomly selected from the 106 significantly differentially expressed genes. Among them, 19 genes were found to be common between both the methods, 12 genes were unique to RNAseq, while remaining 12 genes were found to be unique to microarray (Additional file 1: Table S4). The expression levels were found to be highly reliable for genes that are determined to be significantly differentially expressed by RNA-seq $\left(\mathrm{r}_{\mathrm{s}}=0.94 ; \mathrm{p}\right.$-value $\left.<0.0001\right)$ as well as microarray $\left(r_{s}=0.97\right.$; $p$-value $\left.<0.0001\right)$. For the consensus genes, microarray had a slightly higher correlation with qRT-PCR than RNA-seq (Figures 3A and 3B).

We further plotted the percentage of genes that deviated in the magnitude of FC quantified by RNA-seq and microarray with respect to qRT-PCR (Figures 3C and $3 \mathrm{D})$. For most of the genes, the magnitude of $\mathrm{FC}$ quantified by RNA-seq and microarray were relatively higher, when compared to qRT-PCR (fold difference $>1$ ). Overall, the magnitude of FC quantified by RNA-seq was in consistence with qRT-PCR based quantification (Figure 3C). For microarray, the magnitude of FC was observed to be consistent with qRT-PCR for a majority of genes, however, we also noticed outlier genes with a 9-times higher FC magnitude (Figure 3D).

For the subset of 12 genes that were found to be uniquely determined by RNA-seq, the magnitude of FC quantified by RNA-seq correlated moderately with qRT-PCR $\left(\mathrm{r}_{\mathrm{s}}=0.58\right.$; p-value 0.05) (Figure 4A; Additional file 1: Table S5). The 12 genes found to be uniquely detected by microarray had a correlation of $r_{s}=0.92$ (p-value 0.002) with qRT-PCR (Figure 4B; Additional file 1: Table S5). These correlations are slightly lower when compared to the consensus genes $\left(r_{s} \geq 0.94\right)$. This indicated that the expression levels are more reliable for the genes that are determined to be significantly differentially expressed by both RNA-seq and microarray rather than by any one method. Moreover, it also indicated that there is a lot of variation in the magnitude of FC quantified by RNAseq and qRT-PCR. We further evaluated this variation i.e. deviation from the magnitude of FC, by plotting the frequency histogram for the 12 genes unique to RNA-seq 

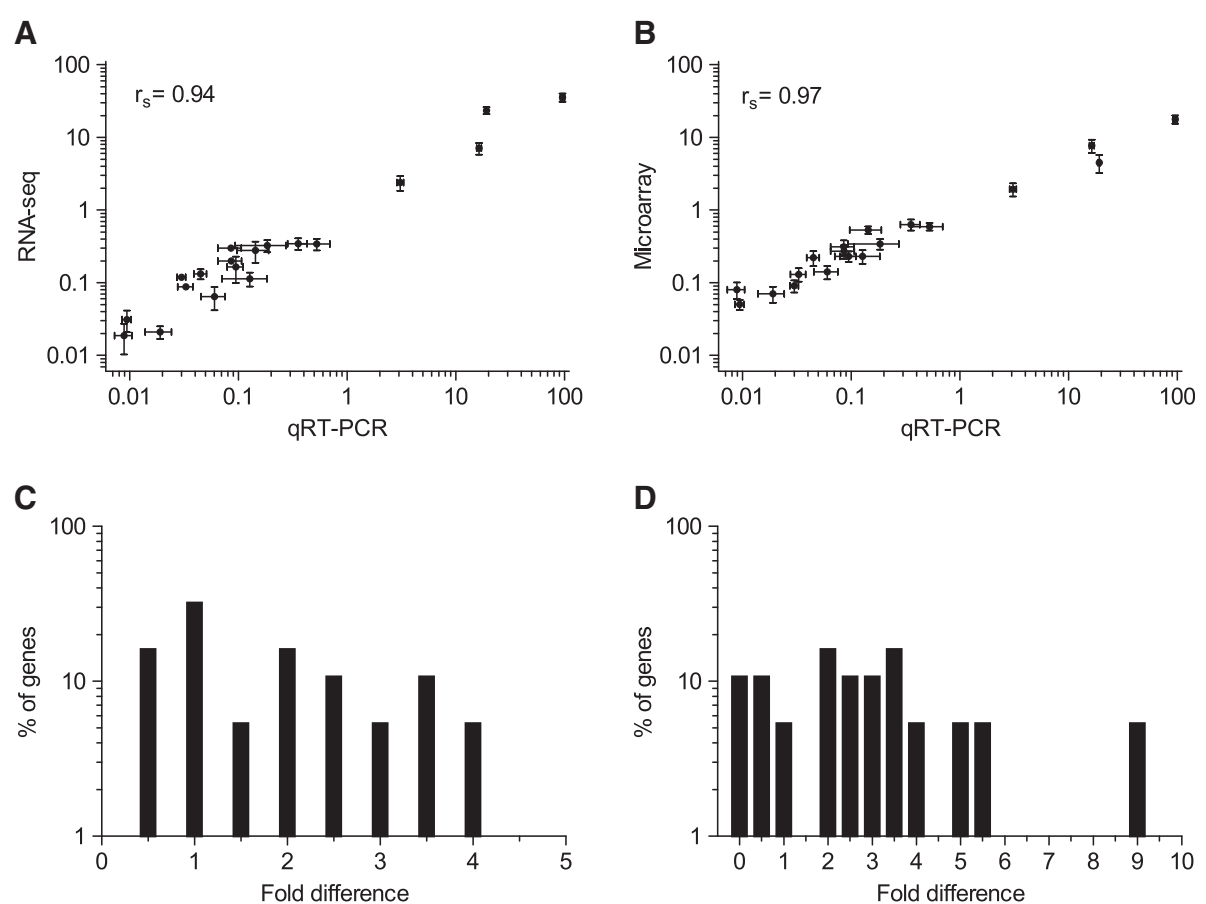

Figure 3 Comparison of expression levels quantified by RNA-seq and microarray with qRT-PCR. (A) Comparison of expression levels determined by RNA-seq with qRT-PCR. (B) Comparison of expression levels determined by microarray with qRT-PCR (C) Frequency histogram showing the percentage of genes with the fold difference between RNA-seq and GRT-PCR, with a bin width of 0.5. (D) Frequency histogram showing percentage of genes with the fold difference between microarray and GRT-PCR, with a bin width of 0.5 .

A

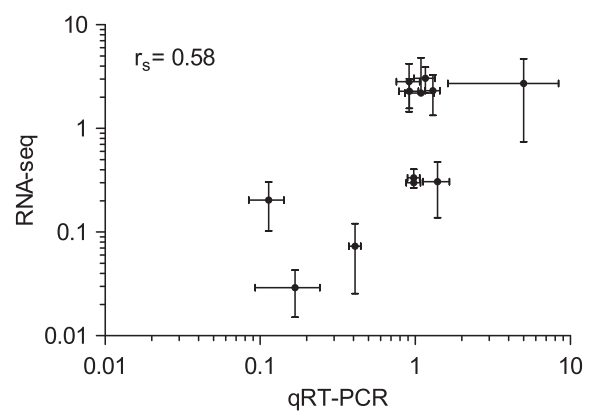

C

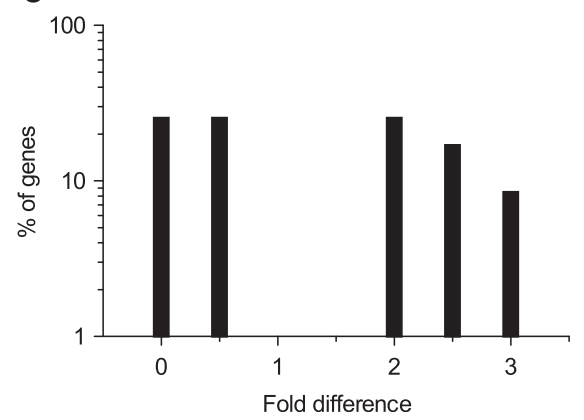

B

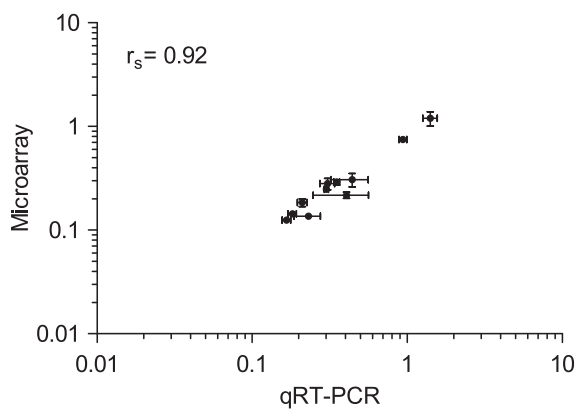

D

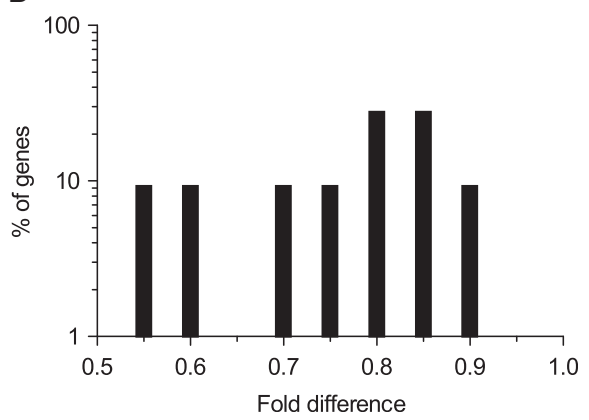

Figure 4 Comparison of expression levels of genes that are uniquely determined by RNA-seq and microarray with that of qRT-PCR. Expression levels for the set of selected genes quantified by (A) RNA-seq, and (B) microarray with that of qRT-PCR. Frequency histogram showing percentage of genes deviating from the magnitude of FC, quantified by RNA-seq $(\mathbf{C})$, and microarray $(\mathbf{D})$ with respect to qRT-PCR. Bin width of 0.5 and 0.05 are used respectively. 
(Figure 4C) and microarray (Figure 4D). For the genes unique to RNA-seq, we observed that none of them had the same magnitude of $\mathrm{FC}$, with $50 \%$ genes having 0 to 0.5 -time lower and for the remaining $50 \%$ of the genes the magnitude of FC was observed to be 2 to 3-time higher, when compared to qRT-PCR (Figure 4C). Because of this inconsistence in the magnitude of FC, the expression levels are moderately correlated. For the genes unique to microarray, we observed a good consistence in the magnitude of FC with qRT-PCR (Figure 4D).

\section{Comparison in terms of detection of genes encoding T3SS and effectors}

Extensive and detailed studies have been carried out since past three decades in cataloguing the target genes of HrpX in the genus Xanthomonas using various genetic and biochemical methods [32,38,39,50-55]. HrpX is known to regulate hrp gene cluster that encodes the type III secretion system (T3SS) and effectors [31,56]. T3SS are specialized macromolecular machinery that act as a nano-injector to translocate the effector proteins into the cytoplasm of host plant cells [50]. These translocated effectors manipulate the host cellular processes by altering signal transduction, transcriptional activities like suppression of basal plant defense responses, and protein turnover in host cells for the benefit of the pathogen [50]. The T3SS machineries are evolutionarily conserved across many Gram-negative animal- and plantpathogenic bacteria [57].

Xcc is comprised of 25 hrp genes, including 19 hrpconserved $(h r c)$ and $6 h r p$-associated (hpa) genes that encode the T3SS [58]. These genes are clustered in a $\sim 25 \mathrm{~kb}$ region spanning from 462712 to 488334 bp of the genome [32]. We applied statistically significant differentially expressed gene list that were derived from RNA-seq and microarray methods to this cluster. We counted for the number of known hrp cluster genes, which passed the FC and FDR cut-off thresholds from RNA-seq and microarray methods (Table 1). Among the 25 hrp cluster genes, 16 (64\%) were detected by both RNA-seq and microarray methods. Six genes were found to be uniquely detected by microarray, whereas, none uniquely detected by RNA-seq (Table 1). Three genes namely, $h r c C$, hpa2, and $h p a A$ could not pass our statistical cut-off criteria by any of the methods, although they followed the same qualitative expression pattern. We further quantified the deviation in the magnitude of FC for the 16 known hrp genes, found in consensus between RNA-seq and microarray (Figure 5A). The magnitude of $\mathrm{FC}$ for $5 \%$ genes found to be same, while for the remaining $95 \%$ genes it was found to be between 1.2 to 1.8-time higher in RNA-seq than in microarray. Even though, microarray overall detected more genes from hrp cluster, RNA-seq reported higher magnitude of FC (Table 1).

Xcc also encodes 25 putative effector genes regulated by $\operatorname{HrpX}$, which meditate the interaction with the host plant, hence determine the host specificity [55]. Since XAC2785, XAC1210 and XAC1209 were considered as pseudo or inactive genes, they were excluded from our analysis. We tabulated how many of these genes were detected by RNA-seq and microarray methods with their corresponding $\log _{2} \mathrm{FC}$ values along with $\mathrm{p}$-value and FDR from the respective methods (Table 2). In total, 10 (45.5\%) genes were detected by both the methods. RNAseq and microarray uniquely detected one and three genes respectively. The remaining 9 genes (36.4\%) were neither detected by RNA-seq nor by microarray, since they could not pass both the FC and FDR cut-offs (Table 2). For the 10 consensus genes, we calculated the fold differences in the magnitude of FC quantified by RNA-seq with respect to microarray. None of the genes had the same magnitude of FC between the two methods. Microarray estimated higher magnitude of FC for $\sim 64 \%$ genes than RNA-seq, while RNA-seq estimated 1.2 to 1.8-time higher magnitude of FC for the remaining $\sim 36 \%$ genes (Figure $5 \mathrm{~B}$ ). In contrast to hrp gene cluster, where microarray qualitatively outperformed RNA-seq in its ability to detect more genes, here RNA-seq complemented quantitatively with higher confidence by reporting higher magnitude of FCs. Thereby, for the effector gene data set, RNA-seq and microarray complemented each other both qualitatively as well as quantitatively.

Overall, considering T3SS and effector genes, in total there are 47 genes, from which, 26 genes (55\%) were detected by both RNA-seq and microarray (Tables 1 and 2). RNA-seq uniquely detected 1 gene (2\%), whereas, microarray detected 9 genes (19\%). Remaining 11 genes (23\%) were not detected by either one of the methods by failing to pass the cut-off threshold (Tables 1 and 2). Further, considering only the genes that are detected by at least one method, $72 \%$ of the known were detected by both methods, while remaining $28 \%$ were detected by either one of the methods.

\section{Genes uniquely detected by RNA-seq and microarray}

Among the 87 statistically significant differentially expressed genes from RNA-seq, 42 (39.63\%) genes were found to be uniquely detected by this method (Additional file 2: Figure FS2). Of these 42 genes, 17 were found to be down-regulated, while 25 were up-regulated (Additional file 1: Table S4). Nearly $98 \%$ of these genes (41 of 42 unique) could not pass the FC cut-off threshold by microarray. The only exception is the gene fliO (XAC1945) that encodes a flagellar protein for flagellum apparatus, which passed the FC cut-off, but failed with 
Table 1 Summary of Type III secretion system (T3SS) hrp cluster genes detected by RNA-seq and microarray

\begin{tabular}{|c|c|c|c|c|c|c|c|c|}
\hline \multirow[t]{2}{*}{ Locus Tag } & \multirow[t]{2}{*}{ Gene Symbol } & \multicolumn{3}{|c|}{ RNA-seq } & \multicolumn{3}{|c|}{ Microarray } & \multirow[t]{2}{*}{ Detected by } \\
\hline & & $\log _{2} F C$ & p-value & FDR & $\log _{2} F C$ & p-value & FDR & \\
\hline XAC0412 & $\operatorname{hrcN}$ & -2.2355 & $7.66 \mathrm{E}-09$ & $1.27 \mathrm{E}-06$ & -0.8217 & $0.00 E+00$ & $0.00 E+00$ & $t$ \\
\hline XAC0409 & hreJ & -3.1488 & 4.20E-15 & 1.40E-12 & -2.1840 & $0.00 E+00$ & $0.00 E+00$ & t \\
\hline XAC0406 & $\operatorname{hrcU}$ & -2.6729 & $1.01 \mathrm{E}-13$ & $2.56 \mathrm{E}-11$ & -1.0507 & $0.00 \mathrm{E}+00$ & $0.00 \mathrm{E}+00$ & 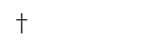 \\
\hline XAC0405 & hrcV & -1.5755 & $3.27 \mathrm{E}-08$ & 4.88E-06 & -0.8427 & 4.00E-05 & $2.58 \mathrm{E}-03$ & t \\
\hline XAC0407 & hrpB1 & -3.9638 & $7.53 \mathrm{E}-28$ & $3.61 \mathrm{E}-25$ & -2.8603 & $0.00 E+00$ & $0.00 E+00$ & + \\
\hline XAC0408 & hrpB2 & -2.8155 & $2.48 \mathrm{E}-09$ & 4.67E-07 & -1.9507 & $0.00 \mathrm{E}+00$ & $0.00 E+00$ & t \\
\hline XAC0410 & hrpB4 & -1.9274 & 7.42E-05 & $6.05 \mathrm{E}-03$ & -1.5237 & $0.00 \mathrm{E}+00$ & $0.00 \mathrm{E}+00$ & $\dagger$ \\
\hline XAC0403 & hrcQ & -2.0615 & $6.36 \mathrm{E}-07$ & 7.64E-05 & -0.8647 & $0.00 E+00$ & $0.00 E+00$ & t \\
\hline XAC0402 & hrch & -1.7123 & 4.73E-06 & 5.53E-04 & -0.8677 & $0.00 \mathrm{E}+00$ & $0.00 \mathrm{E}+00$ & t \\
\hline XAC0399 & hrpD5 & -1.7287 & $2.67 \mathrm{E}-10$ & 5.50E-08 & -1.5487 & $0.00 \mathrm{E}+00$ & $0.00 \mathrm{E}+00$ & $\dagger$ \\
\hline XAC0398 & hrpD6 & -1.5446 & $5.85 \mathrm{E}-07$ & 7.43E-05 & -1.6347 & $0.00 \mathrm{E}+00$ & $0.00 \mathrm{E}+00$ & $\dagger$ \\
\hline XAC0397 & hrpE & -2.1535 & 7.67E-16 & $2.76 \mathrm{E}-13$ & -1.8163 & $0.00 \mathrm{E}+00$ & $0.00 \mathrm{E}+00$ & t \\
\hline XAC0394 & hrpF & -2.0517 & $7.04 \mathrm{E}-15$ & $2.17 \mathrm{E}-12$ & -1.2113 & $0.00 E+00$ & $0.00 E+00$ & t \\
\hline XAC0416 & hpal & -5.0096 & 1.49E-51 & $1.29 \mathrm{E}-48$ & -4.2917 & $0.00 \mathrm{E}+00$ & $0.00 \mathrm{E}+00$ & t \\
\hline XAC0396 & $h p a B$ & -1.5429 & $1.56 \mathrm{E}-07$ & $2.11 \mathrm{E}-05$ & -1.2527 & $0.00 \mathrm{E}+00$ & $0.00 \mathrm{E}+00$ & $\dagger$ \\
\hline XAC0393 & hpaF & -0.9235 & 1.96E-04 & $1.34 \mathrm{E}-02$ & -0.6083 & $1.00 \mathrm{E}-05$ & $8.10 \mathrm{E}-04$ & t \\
\hline XAC0411 & hrpB5 & -1.9690 & 3.92E-03 & 1.38E-01 & -0.8457 & $0.00 \mathrm{E}+00$ & $0.00 E+00$ & $\psi$ \\
\hline XAC0401 & hrcs & -1.0156 & 4.00E-02 & 4.71E-01 & -1.0837 & $0.00 \mathrm{E}+00$ & $0.00 \mathrm{E}+00$ & $\psi$ \\
\hline XAC0404 & hpaP & -1.2673 & 1.10E-02 & 2.74E-01 & -1.1110 & $0.00 \mathrm{E}+00$ & $0.00 \mathrm{E}+00$ & $\psi$ \\
\hline XAC0395 & XAC0395 & -1.0817 & 4.73E-02 & $5.08 \mathrm{E}-01$ & -0.8640 & $0.00 E+00$ & $0.00 E+00$ & $\psi$ \\
\hline XAC0415 & hrcC & -0.2713 & $2.49 \mathrm{E}-01$ & 8.27E-01 & -0.4053 & 4.75E-03 & $1.78 \mathrm{E}-01$ & $\$$ \\
\hline XAC0413 & hrpB7 & -1.2107 & $1.08 \mathrm{E}-02$ & 2.74E-01 & -0.6590 & $0.00 \mathrm{E}+00$ & $0.00 \mathrm{E}+00$ & $\psi$ \\
\hline XAC0417 & hpa2 & -1.4130 & 8.33E-03 & 2.31E-01 & -0.4610 & 4.40E-04 & 2.64E-02 & $\$$ \\
\hline XAC0400 & hpaA & -1.0585 & $2.76 \mathrm{E}-03$ & 1.10E-01 & -0.7763 & $9.74 \mathrm{E}-03$ & 2.05E-01 & $\$$ \\
\hline XAC0414 & hrct & -1.0474 & 1.10E-02 & 2.74E-01 & -0.6800 & $0.00 \mathrm{E}+00$ & $0.00 \mathrm{E}+00$ & $\psi$ \\
\hline
\end{tabular}

† Consensus between RNA-seq and microarray16 genes (64\%).

$\xi$ Only RNA-seq 0 gene (0\%).

$\psi$ Only microarray 6 genes $(24 \%)$

$\$$ Undetected 3 genes (12\%).

The list of known T3SS hrp cluster genes along with the information about the $\log _{2}$ FC, p-value and FDR value from RNA-seq and microarray experiments.

"Detected by" column assigns by which method the known hrp cluster gene is found to be significantly differentially expressed.

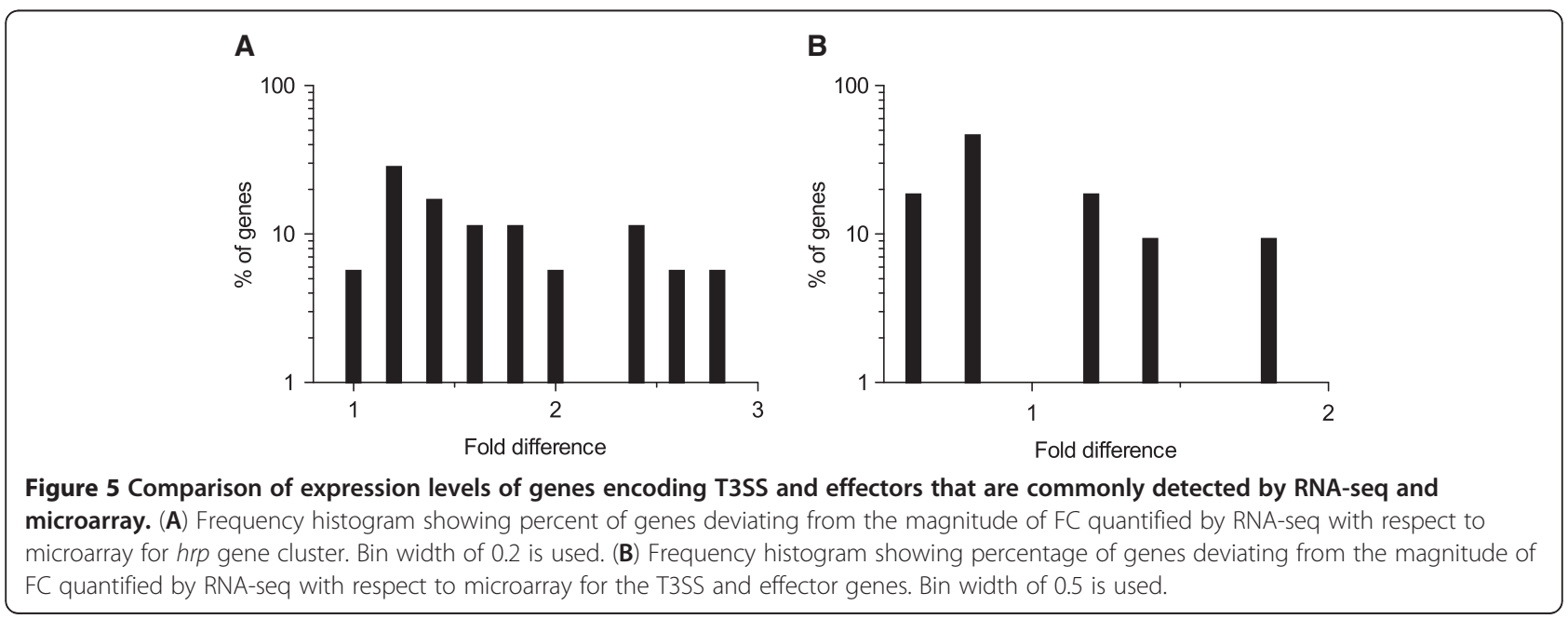


Table 2 Summary of Type III effector genes detected by RNA-seq and microarray

\begin{tabular}{|c|c|c|c|c|c|c|c|c|}
\hline \multirow[t]{2}{*}{ Locus Tag } & \multirow[t]{2}{*}{ Gene Symbol } & \multicolumn{3}{|c|}{ RNA-seq } & \multicolumn{3}{|c|}{ Microarray } & \multirow[t]{2}{*}{ Detected by } \\
\hline & & $\log _{2} F C$ & p-value & FDR & $\log _{2} F C$ & p-value & FDR & \\
\hline XAC0286 & xopE & -1.3432 & $1.21 \mathrm{E}-07$ & 1.69E-05 & -1.1813 & $0.00 \mathrm{E}+00$ & $0.00 \mathrm{E}+00$ & $\dagger$ \\
\hline XACb0011 & avrXacE3 & -0.9098 & $2.20 \mathrm{E}-04$ & $1.51 \mathrm{E}-02$ & -1.6363 & $0.00 \mathrm{E}+00$ & $0.00 \mathrm{E}+00$ & $\dagger$ \\
\hline XAC0754 & xopl & -1.1830 & $5.40 \mathrm{E}-04$ & $3.11 \mathrm{E}-02$ & -0.7287 & $0.00 \mathrm{E}+00$ & $3.00 \mathrm{E}-05$ & t \\
\hline XAC3085 & xopK & -2.1505 & $0.00 \mathrm{E}+00$ & $0.00 \mathrm{E}+00$ & -1.7157 & $0.00 \mathrm{E}+00$ & $0.00 \mathrm{E}+00$ & $\dagger$ \\
\hline XAC2786 & xopN & -3.5117 & $0.00 \mathrm{E}+00$ & $0.00 \mathrm{E}+00$ & -2.9897 & $0.00 \mathrm{E}+00$ & $0.00 \mathrm{E}+00$ & t \\
\hline XAC1208 & хорP & -1.1860 & $1.00 \mathrm{E}-05$ & $6.20 \mathrm{E}-04$ & -0.7583 & $0.00 \mathrm{E}+00$ & $0.00 \mathrm{E}+00$ & $\dagger$ \\
\hline XAC0277 & xopR & -1.1202 & $6.00 \mathrm{E}-05$ & $5.10 \mathrm{E}-03$ & -1.2360 & $0.00 \mathrm{E}+00$ & $0.00 \mathrm{E}+00$ & $\dagger$ \\
\hline XAC0543 & xopX & -3.0765 & $0.00 \mathrm{E}+00$ & $0.00 \mathrm{E}+00$ & -3.4423 & $0.00 \mathrm{E}+00$ & $0.00 \mathrm{E}+00$ & $\dagger$ \\
\hline XAC3230 & xоpAl & -1.4353 & $0.00 \mathrm{E}+00$ & $0.00 \mathrm{E}+00$ & -1.1510 & $0.00 \mathrm{E}+00$ & $0.00 \mathrm{E}+00$ & t \\
\hline XAC2922 & hrpW & -2.0833 & $0.00 \mathrm{E}+00$ & $0.00 \mathrm{E}+00$ & -2.7723 & $0.00 \mathrm{E}+00$ & $0.00 \mathrm{E}+00$ & $\dagger$ \\
\hline XAC4213 & xopAD & -0.8816 & $2.60 \mathrm{E}-04$ & $1.68 \mathrm{E}-02$ & -0.3960 & $2.17 \mathrm{E}-02$ & $2.72 \mathrm{E}-01$ & $\xi$ \\
\hline XAC4333 & xopQ & -0.6779 & 1.95E-02 & $3.51 \mathrm{E}-01$ & -1.1190 & $0.00 \mathrm{E}+00$ & $0.00 \mathrm{E}+00$ & $\psi$ \\
\hline XAC0601 & xopV & -0.5197 & $5.44 \mathrm{E}-02$ & 5.33E-01 & -0.7367 & $0.00 \mathrm{E}+00$ & 2.70E-04 & $\psi$ \\
\hline XAC0076 & avrBs2 & -0.8632 & $1.79 \mathrm{E}-03$ & 7.90E-02 & -0.566 & $5.00 \mathrm{E}-05$ & $3.53 \mathrm{E}-03$ & $\$$ \\
\hline XAC3090 & xopl & -0.3402 & $2.58 \mathrm{E}-01$ & 8.37E-01 & -0.6040 & $0.00 \mathrm{E}+00$ & $0.00 \mathrm{E}+00$ & $\psi$ \\
\hline XAC3224 & $x o p E$ & -0.5716 & $2.45 \mathrm{E}-02$ & 3.85E-01 & -0.2397 & $2.68 \mathrm{E}-02$ & $4.48 \mathrm{E}-01$ & $\$$ \\
\hline XAC2009 & $x o p Z$ & -0.6456 & $9.45 \mathrm{E}-03$ & $2.56 \mathrm{E}-01$ & -0.4160 & 1.30E-04 & $9.38 \mathrm{E}-03$ & $\$$ \\
\hline XAC3666 & хорАK & -0.2756 & 2.89E-01 & 8.59E-01 & -0.2060 & 3.23E-01 & 9.82E-01 & $\$$ \\
\hline XACa0022 & pthAl & 0.0225 & $8.00 \mathrm{E}-01$ & $9.80 \mathrm{E}-01$ & 0.0790 & 6.69E-01 & $9.98 \mathrm{E}-01$ & $\$$ \\
\hline XACa0039 & pthA2 & -0.4501 & 2.09E-01 & 7.97E-01 & 0.0413 & 8.25E-01 & 9.98E-01 & $\$$ \\
\hline XACb0015 & pthA3 & -1.1700 & $3.52 \mathrm{E}-03$ & $1.28 \mathrm{E}-01$ & 0.0723 & 7.13E-01 & $9.98 \mathrm{E}-01$ & $\$$ \\
\hline XACb0065 & pthA4 & -0.3423 & $8.51 \mathrm{E}-01$ & $1.00 \mathrm{E}+00$ & 0.0315 & $7.23 \mathrm{E}-01$ & $9.98 \mathrm{E}-01$ & $\$$ \\
\hline
\end{tabular}

+ Consensus between RNA-seq and microarray 10 genes (45.5\%).

$\psi$ Only microarray 3 genes (13.6\%).

$\xi$ Only RNA-seq 1 genes (4.5\%).

\$ Undetected 8 genes (36.4\%).

The list of known T3SS effector genes along with the information about the $\log _{2} \mathrm{FC}$, $\mathrm{p}$-value and FDR value derived from RNA-seq and microarray experiments.

"Detected by" column assigns by which method the following effector genes are found to be significantly differentially expressed.

FDR threshold. The gene XAC0755 encoding KdpF, a component of an integral membrane potassiumtransporting system [59], is down-regulated by a factor of $3\left(\log _{2}\right.$ FC of 1.6) according to RNA-seq, but, microarray could not capture this, as the probes for this gene were missing on the chip. This shows the limitation of microarray, where probes for all the genes need to be defined while designing the chip. Furthermore, four genes uniquely found by RNA-seq are involved in signal transduction and gene regulation, i.e. XAC4116 encoding a serine/threonine kinase, XAC1819 encoding a tryptophan-rich sensory protein, and two regulatory genes XAC3026, and XAC3363, whose function in citrus canker disease development remain to be explored. Furthermore, 21 genes (24\%) are currently annotated as hypothetical proteins (Additional file 1: Table S6). Among them, four hypothetical proteins XAC0854, XAC4131, XAC1203, and XACb0064 were predicted to be T3SS secreted while 7 hypothetical proteins, XAC3275, XAC3680, XAC1943, XAC0527, XAC0599,
XAC0239, and XAC0755 were predicted to be Type 2 Secretion System (T2SS) substrates (Additional file 1: Table S6) by Effective database [60]. Gram-negative bacteria employ T2SS to transport proteins to the extracellular milieu, where the T2SS exo-proteins containing $\mathrm{N}$-terminal signal peptides are used for inner-membrane translocation through either the Sec translocon or the Tat complex [61]. Genes encoding proteins secreted by T3SS and T2SS have been experimentally proved to be regulated by $\operatorname{HrpX}[33,62,63]$.

Among the 64 statistically significant differentially expressed genes from microarray, 19 (29.7\%) genes were found to be uniquely detected by this method (Additional file 2: Figure FS2). 18 were found to be down-regulated, while one gene was up-regulated (Additional file 1: Table S4). Unlike that of RNA-seq, nearly $63 \%$ genes (12 of 19 unique) could pass the FC cut-off threshold, but failed to pass the FDR threshold by RNA-seq. The remaining $37 \%$ genes ( 7 of 19 
unique) could not pass both FC and FDR cut-off threshold. Furthermore, six genes were found to be hypothetical. Among them XAC2876, XAC1241, and XAC2370 were predicted as T2SS substrates. XAC1241 predicted as a T2SS substrate, shared $73 \%$ identity with a putative secreted protein from $X$. campestris pv. vesicatoria strain 85-10. Another T2SS candidate XAC2370 shared 95\% identity with a secreted protein from X. fuscans subsp. aurantifolii str. ICPB 10535. XAC1124 shared $100 \%$ identity with MEKHLA domain protein from $X$. axonopodis pv. punicae str. LMG 859 [33]. This domain is found in bacteria associated with plants. It further shares similarity with the PAS domain and might be involved in light, oxygen, and redox potential sensation [64].

\section{Comparison at the level of functional annotations of genes}

For comparison based on the biological function for the differentially expressed genes from RNA-seq and microarray, we utilized the ClueGO to integrate the Gene Ontology (GO) [65] terms and KEGG [66] pathway terms and create a functionally organised GO/KEGG network. Functional annotation with biological processes category resulted in $13(14.94 \%)$ genes found from cluster for RNA-seq, while for microarray it was 12 (19.35\%).

The ClueGO overview pie chart highlighted that significant proportion of the genes differentially regulated are involved in "protein secretion by the T3SS" by both RNA-seq and microarray (Additional file 3: Figure FS3A \& D). Additionally, RNA-seq also identified genes involved in "secretion activity by cell" as well as "single organism catabolic process" (Additional file 3: Figure FS3A). On the other hand, microarray highlighted the genes involved in "protein transmembrane transport", "polycyclic aromatic hydrocarbon degradation" and "establishment of localization in cell" (Additional file 3: Figure FS3D). Majority of the genes are involved in "bacterial secretion system", as shown by both RNA-seq and microarray. Also the differentially expressed genes are found to be significantly involved in the "transport of monovalent inorganic cation" (Additional file 3: Figure FS3B) and "protein transport" (Additional file 3: FS3E). Genes have also been found uniquely by microarray as significantly involved in "polycyclic aromatic hydrocarbon degradation" (Additional file 3: Figure FS3E). Genes from RNA-seq have been found to be involved in "riboflavin metabolism" as well as "single organism catabolic process" (Additional file 3: Figure FS3B). Further, visualization of the functionally grouped annotation network for the differentially regulated genes derived from RNA-seq (Additional file 3: Figure FS3C) and microarray
(Additional file 3: Figure FS3F) methods highlighted the relationships between the terms. RNA-seq highlighted "protein secretion by the T3SS" along with the "small molecule catabolic process", while microarray reflected "polycyclic aromatic hydrocarbon degradation" and "establishment of localization in cell", as the most significant terms of the group. This analysis also showed that RNA-seq and microarray together provide more comprehensive functional information than the individual methods.

\section{PIP box detection}

HrpX is known to regulate the target gene expression by specifically binding to PIP box motif present in the cis-regulatory regions. PIP box consists of direct repeats of "TTCGC" with a spacer of 8 to 26-bps in between the repeats, even though ideally 8 -bps and 15 -bps are considered as the canonical PIP box [37]. We exploited this feature and looked for PIP boxes in the promoter regions of the 106 significantly differentially expressed genes (Additional file 4). All the 106 differentially expressed genes could be assigned to 90 transcriptional units based on MetaCyc database [67] (Additional file 1: Table S8). However for simplicity, genes under the control of the same cis-regulatory regions were counted separately. Among the consensus 45 genes, $36(80 \%)$ were shown to have canonical PIP boxes (Figure 6A, Additional file 1: Table S7). Of the 42 genes that are uniquely determined by RNA-seq, 13 (31\%) genes were confirmed to have PIP boxes; whereas, among the 19 genes that are uniquely determined by microarray 11 (57.8\%) genes were confirmed to have PIP boxes (Figure 6A, Additional file 1: Table S7). In this study, we identified newly PIP box motif in 7 (19.4\%) genes among consensus, 13 (100\%) genes unique to RNA-seq and 1 (9\%) gene unique to microarray (Figure 6B). Overall, 60 of the 106 ( 57\%) significantly differentially expressed genes were confirmed to have PIP boxes in their cis-regulatory regions (Additional file 1: Table S7, Additional file 4). The presence of PIP box confirmed that these genes may be directly regulated by $\operatorname{HrpX}$, while the remaining 46 that do not have PIP boxes may be indirectly regulated by $\operatorname{HrpX}$ via the other transcription factors. In this regard, we looked for genes with sequence specific DNA binding activity in the 106 differentially expressed genes. Six genes namely hrpG, pcaQ, blal, XAC3026, XAC3445, and XAC3446 were known to have sequence specific DNA binding activity according to GO annotation. Among them, XAC3446, XAC3445, and blaI have been newly identified in this study containing PIP box motif (Additional file 1: Table S7, Additional file 4). Thereby these 3 transcription regulators are directly regulated by $\mathrm{HrpX}$, which in turn we assume regulate the 46 genes, which do not 

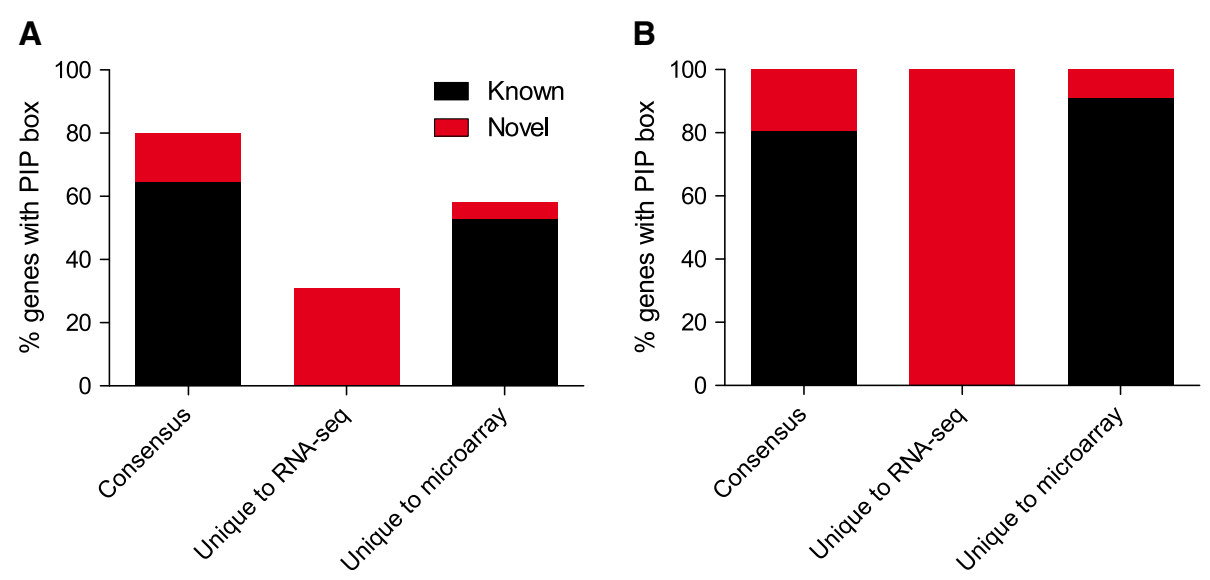

Significantly differentially expressed genes

Figure 6 Statistics of HrpX binding sites in the cis-regulatory regions of significantly differentially expressed genes from RNA-seq and microarray. The genes belonging to consensus and unique to each method are shown (A) Percentage of genes containing PIP box in the cis-regulatory regions of genes that belong to three different groups are shown. The known (black bar) and novel (red bar) are indicated. (B) Only genes with PIP box are shown, percentage of which already known (black bar) and novel (red bar) are indicated.

contain the PIP box motif and hence indirectly regulated by HrpX. The DNA binding signatures for many of these transcription factors are unknown; hence, obscure the further confirmation of regulation by these transcription factors. Nevertheless, the fact that many of the genes that were uniquely determined by each method showed a clear PIP box in their cisregulatory regions reiterates that RNA-seq and microarray complement each other.

\section{Discussion}

Currently, RNA-seq is becoming the preferable choice for gene expression profiling in place of microarrays. Although, all the parameters that influence the various aspects of this method are yet to be understood completely, RNA-seq undoubtedly is playing a very important role in deciphering the complexity of the transcriptome by giving a new direction to isoforms, allelic expression, untranslated regions, splice junctions, antisense regulation and intragenic expression [10,16,29,68-74]. Several studies have begun to investigate on the parameters like sequencing depth, precision, GC bias, length bias, lane effects, and processing artifacts $[16,29,48,75-77]$. On the other hand, microarrays are in usage for more than two decades. Therefore, most of the biases inherent to this method have become more apparent [78]. For instance, biases in the hybridization of the samples labeled with Cyanine5 (Cy5) and Cyanine3 (Cy3) are sufficiently explored, and currently several approaches are practiced to minimize such effects [79-82]. Further, systematic variability like influence of the image scanner settings on the dye intensity measurements have now been robustly handled by applying various normalization techniques [83-86]. Despite these developments, some inherent genes-specific biases like differential hybridization efficiencies of the labeled target transcript to the same probe are still found to be inevitable in microarrays. In RNA-seq as well as microarray, all these known and unknown parameters influence the final outcome. Therefore, in this study, we focused on the assessment of RNA-seq and microarray based on the final outcome i.e. statistically significant differentially expressed genes.

In comparison with previous RNA-seq studies, with a sequence coverage of $97 \%$ we observed for our data set, is in consistence with the reported $89.5 \%$ to $95 \%$ coverage observed in other bacterial RNA-seq studies [87-89]. In our study, RNA-seq has identified more significantly differentially expressed genes (82\%), when compared to microarray $(63 \%)$ as in previous studies $[18,29,30]$. The overall correlation $\left(r_{s} 0.76\right)$ in the magnitudes of FC for the consensus genes between the two methods was found to be similar or higher than previous studies $[18,29,30,72]$. Furthermore, our comparison analysis with qRT-PCR suggested that the expression levels were highly reliable for those genes that were determined to be differentially expressed by both RNA-seq and microarray. Hence, confirming the differential expression of genes by multiple methods reduces false positives thereby enhances the biological discovery.

Even though microarray overall outperformed RNAseq by detecting more known HrpX target genes from the T3SS in hrp cluster by satisfying both FC and FDR cut-off threshold, in principle RNA-seq also detected genes $h r p B 5, h r c S$, hpaP, XAC0395, hrpB7, and $h r c T$, in terms of FC, but failed to pass FDR threshold. This parameter is more directly influenced by error model considered in the statistical method that is used to 
infer the differential expression rather than RNA-seq itself. For the same read counts, one can get slightly different FDR values depending on the statistical method [90]. But the implementation of all the statistical methods is not feasible for every dataset. From the T3SS in hrp cluster, three genes namely, $h r c C$, hpa2, and hpaA were not found to be detected by both RNA-seq and microarray, mainly because they fail to pass FDR threshold. Interestingly, our previous microarray analysis confirmed that all these three genes are regulated by HrpX, but only at a later stage of the growth phase by satisfying both FC and FDR cut-off thresholds [33]. This consolidates the regulation of some of the genes at later stages of the growth phase. Further, in case of Type III effector genes, 8 genes $(36.4 \%)$ were not detected by both RNA-seq and microarray within considered cut-off threshold limit. However, among them xopL, avrBs2, xopAK and $x o p Z$ were found to be regulated by $\operatorname{HrpX}$ only at the later stage of the growth phase $\left(\mathrm{OD}_{600}\right.$ time point 0.5$)$, according to our previous microarray analysis [33]. Further, four genes namely, pthA2, pthA1, pthA3, pth $A 4$ were regulated by another transcription regulator $\mathrm{HrpG}$ at early stage of growth phase $\left(\mathrm{OD}_{600}=\right.$ 0.25 and 0.4 ) as observed in our previous study, while another undetected gene $x o p E$ was found to be also regulated by $\mathrm{HrpG}$, but only at $\mathrm{OD}_{600}=0.25$ time point of growth phase [33]. Thereby this study further validated our previous results. Subsequently, both methods detected $100 \%$ of the genes known to be regulated by $\operatorname{HrpX}$ (at time point $\mathrm{OD}_{600}=0.4$ ) without any false positives. Among them, $72 \%$ were detected by both the methods while interestingly $28 \%$ of the known target genes were detected by either one of the methods. Hence, both the methods together could complement each other.

In addition 55 genes $(\sim 51 \%)$ were newly identified as differentially expressed by applying both microarray as well as RNA-seq methods, thereby adding up to the already existing repertoire of $\mathrm{HrpX}$ regulated genes. Furthermore, 46 (83.6\%) genes among them were uniquely identified by either one of the methods. Overall, 21 newly identified genes were found to have PIP box in their promoter regions, wherein 14 (58.3\%) genes were uniquely identified by either RNA-seq or microarray. The presence of the PIP box in the promoter regions of the HrpX-regulated genes uniquely identified by RNAseq and microarray further not only confirmed that these genes are directly regulated by HrpX, but also that these candidates are not false positives. Consequently, $100 \%$ of the known HrpX regulated genes could only be detected together by both the methods, since each method missed out on some of the known genes; hence both the methods together enhance the understanding of HrpX regulome by providing a more comprehensive picture.

\section{Conclusions}

This study has significantly advanced our understanding of the regulome of the critical transcriptional factor HrpX and demonstrates that RNA-seq and microarray complement each other in transcriptome profiling. Consequently, our study demonstrates the advantage of applying multiple transcriptome profiling methods to reveal a more comprehensive picture of a transcriptome, rather than relying solely on one method.

\section{Methods}

\section{Bacterial strains and growth conditions}

The wild-type $X$. citri subsp. citri [32], and the hrpX mutant strains used in this study were described in our previous study [33]. Both the strains were grown at $28^{\circ} \mathrm{C}$ in nutrient broth (NB), on nutrient agar (NA), or in NYG medium [91]. Antibiotics rifamycin and kanamycin were added to the media at $50 \mu \mathrm{g} / \mathrm{ml}$ final concentrations.

\section{RNA extraction}

Total RNA was extracted from the wild-type and the $h r p X$ mutant strains as described in our previous study [33]. Briefly, strains from NA plates were grown in NB medium at $28^{\circ} \mathrm{C}$ until mid-exponential phase. Cultures were harvested by centrifugation and inoculated in to nutrient-deficient XVM2 medium, after washing the pellet once with the same medium. Cultures were finally harvested for RNA extraction, when the optical density at $600 \mathrm{~nm}$ reached the value of 0.4 , and mixed immediately with RNAprotect bacterial reagent (Qiagen, Valencia, CA, and U.S.A.). Total RNA was extracted from each replicate separately using RiboPure bacteria kit (Ambion, Austin, TX, USA), according to manufacturer's instructions. Genomic DNA contamination from the extracted RNA samples was removed using TURBO DNA-free kit (Ambion). Amount and the quality of the RNA samples was initially determined using NanoDrop ${ }^{\text {m }}$ 1000 spectrophotometer (NanoDrop Technologies, Inc., Wilmington, DE). Samples with absorbency at 260/280 and $260 / 230 \mathrm{~nm}$ ratios $>2$ were subjected to further processing. Three biological replicates of the wild-type and the $h r p X$ mutant samples were used for RNA-seq analysis.

\section{Microarray data}

The microarray data used in this study was generated during our previous study [33]. Three unique 60-mer oligonucleotide probes were designed for each of the 4,427 protein coding genes of $X$. citri subsp. citri [33]. 8by-15-K DNA microarray chips covering the whole genome were implemented under the Agilent platform. 
These microarrays were processed at the Interdisciplinary Center for Biotechnology Research Microarray Core Facility, University of Florida. The raw data is available at National Center for Biotechnology Information (NCBI) Gene Expression Omnibus (GEO) data repository under the accession number GSE24016 [33].

\section{mRNA enrichment and RNA-seq}

Total RNA samples were enriched for mRNA, by depleting rRNA using MICROBExpress kit from Ambion following the manufacturer's instructions. Enriched samples were checked for integrity using Agilent 2100 Bioanalyzer (Agilent Technologies, Santa Clara, CA, USA). RNA samples that passed the quality control were sequenced using the Illumina Genome Analyzer IIx (GAIIx) system by following the standard protocol at the Center for Genome Analysis at Yale University. Real-time analysis and base calling were performed using the CASAVA v1.6 pipeline. The raw sequence data has been submitted to the NCBI Sequence Read Archive and assigned with an accession number SRA052842.

\section{Reads mapping and statistical analysis}

The $X$. citri subsp. citri whole genome sequence consisting of one chromosome [GenBank: NC_003919.1], and two plasmids [GenBank: NC_003921.3 and NC_003922.1], along with the annotation information were downloaded from NCBI repository (ftp://ftp.ncbi.nih.gov/genomes/ Bacteria/). Quality-filtered reads were aligned on to the genome using CLC Genomics Workbench v4.7.2 (CLC bio, Aarhus, Denmark). Reads uniquely aligned to each gene were tabulated from each replicate separately. Differentially expressed genes were estimated using DESeq package [92], available under the open-source Bioconductor suite of programs [93]. DESeq is a powerful tool to estimate the variance in RNA-seq data and test for differential expression [92]. As an input, DESeq accepts a table of read counts for each gene from different biological replicates, and estimates the differentially expressed genes using negative binomial distribution [92]. Statistically significant differentially expressed genes from both microarray and RNA-seq data were obtained by applying a cutoff threshold of FDR $\leq 0.05(5 \%)$ and an absolute $\log _{2}$ fold-change $\geq 0.6$.

\section{Bioinformatics analysis}

Similarity searches were performed online using positionspecific iterative BLAST (PSI-BLAST) at NCBI site against non-redundant protein database [94]. T3SS and T2SS predictions were performed using Effective database [60]. The promoter regions of the significantly differentially expressed genes were retrieved manually using NCBI genome browser to look for the presence of PIP boxes. The differentially expressed genes were assigned to the transcriptional units by referring to the MetaCyc database [67]. Biological interpretation of the differentially expressed genes was carried out using the ClueGO v1.5 [95], a Cytoscape plug-in [96].

\section{qRT-PCR}

All the qRT-PCR assays were performed as detailed elsewhere [33]. Briefly, gene-specific primers were designed for the selected genes using PrimerQuest ${ }^{\mathrm{SM}}$ from Integrated DNA technologies (IDT), Coralville, Iowa (Additional file 1: Table S6). qRT-PCR experiments were performed in triplicates, at least three times for each gene using 7500 fast real-time PCR system (Applied Biosystems, Foster City, CA, USA), using a QuantiTect SYBR green RT-PCR kit (Qiagen) with similar results, by following the manufacturer's instructions. The relative fold change of target gene expression was calculated using $16 \mathrm{~S}$ rRNA as an endogenous control with the formula $2^{-\Delta \Delta C T}$ [97].

\section{Data availability}

The raw RNA-seq data from this study is deposited at the NCBI sequence read archive (http://www.ncbi.nlm. nih.gov/Traces/sra/sra.cgi), under the accession number SRA052842, while the raw microarray data is available at the NCBI Gene Expression Omnibus (http://www.ncbi. nlm.nih.gov/geo) with the accession number GSE24016.

\section{Additional files}

Additional file 1: The following excel format file contains the following $\mathbf{8}$ additional tables: Table S1: Summary of RNA-seq reads from wild-type and hrpX mutant strains of X. citri subsp. citri. Table S2: List of genes that are called by both RNA-seq and microarray. Table S3: List of genes that are uniquely called by RNA-seq and microarray. Table S4: List of statistically significant differentially expressed genes by RNA-seq and microarray filtered by cut-off thresholds. Table S5: List of randomly selected genes for the comparison with qRT-PCR from the statistically significant differentially expressed genes from RNA-seq and microarray. Table S6: Gene specific primers used in qRT-PCR experiment. Table S7: Summary of bioinformatics analysis of statistically significant differentially expressed genes to be part of Type III Secretion System (T3SS) and Type II Secretion System (T2SS) along with the occurrence of PIP box. Table S8: List of 90 transcriptional units from X. citri subsp. citri to which the 106 differentially regulated genes belong.

Additional file 2: Contains the following two additional figures, Figure FS1: Venn diagram summarizing genes called by both technologies, when comparison is carried out between the total currently annotated open reading frames (ORFs) available transcripts from the transcriptome of $X$. citri subsp. citri. Fold-change values are available from RNA-seq (4323) and microarray (4349). Gene's called by both technologies are indicated by the overlap between the two circles. 4312 are found in consensus, while 11 and 37 are unique to RNA-seq and microarray respectively. Figure FS2: Venn diagram summarizing genes that are significantly differentially expressed determined by RNA-seq and microarray. Gene's common to both methods are indicated by the overlap between the two circles.

Additional file 3: Figure FS3 - Comparison at the level of the functional annotations of the significantly differentially expressed genes from RNA-seq and microarray. GO term and KEGG pathway 
information enrichment analysis is shown for the genes from RNA-seq (left panel) and microarray (right panel). The overview of the analysis is shown in the form of pie chart for gene set from RNA-seq (A), and microarray (D). The histogram shows the number of genes associated with terms for the genes from RNA-seq (B) and microarray (E). Significantly enriched terms are indicated with '*'. The terms that are functionally related are shown as a network with terms as nodes and relatedness is indicated with thickness of the edges that is based on their kappa score. The most significant term per group are shown for genes from RNA-seq (C) and microarray (F).

Additional file 4: Figure FS4 - Snapshot of the PIP box motif present in the cis-regulatory region of significantly differentially expressed genes is shown in the context of the whole genome of $X$. citri subsp. citri. The absolute position of each PIP box motif occurrence is shown on the whole genome map along with the -10 'TATA' regions and the gene start site.

\section{Competing interests}

We declare no competing interests.

\section{Authors' contributions}

NW conceived the idea and initiated the study. SK performed analysis and interpretation of the data and wrote the manuscript. QY carried out the PCR experiments. YG participated in the study design, sample and data collection, and data interpretation. NW participated in interpretation of data and writing the manuscript and supervised the overall work. All authors read and approved the final manuscript.

\section{Acknowledgements}

We wish to acknowledge Gabriela Bindea for providing annotation files for ClueGO software. This work was supported by United States Department of Agriculture - NIFA Special Citrus Canker Grant Project 94677.

Received: 18 July 2012 Accepted: 5 November 2012 Published: 15 November 2012

\section{References}

1. Wang Z, Gerstein M, Snyder M: RNA-Seq: a revolutionary tool for transcriptomics. Nat Rev Genet 2009, 10:57-63.

2. Baginsky S, Hennig L, Zimmermann P, Gruissem W: Gene expression analysis, proteomics, and network discovery. Plant Physiol 2010, 152:402-410.

3. Cloonan N, Forrest AR, Kolle G, Gardiner BB, Faulkner GJ, Brown MK, Taylor DF, Steptoe AL, Wani S, Bethel G, et al: Stem cell transcriptome profiling via massive-scale mRNA sequencing. Nat Methods 2008, 5:613-619.

4. Costa V, Angelini C, De Feis I, Ciccodicola A: Uncovering the complexity of transcriptomes with RNA-Seq. J Biomed Biotechnol 2010, 2010:853916.

5. DeRisi J, Penland L, Brown PO, Bittner ML, Meltzer PS, Ray M, Chen Y, Su YA, Trent JM: Use of a CDNA microarray to analyse gene expression patterns in human cancer. Nat Genet 1996, 14:457-460

6. Ekins R, Chu FW: Microarrays: their origins and applications. Trends Biotechnol 1999, 17:217-218.

7. Fodor SP, Rava RP, Huang XC, Pease AC, Holmes CP, Adams CL: Multiplexed biochemical assays with biological chips. Nature 1993, 364:555-556.

8. Hegde P, Qi R, Abernathy K, Gay C, Dharap S, Gaspard R, Hughes JE, Snesrud E, Lee N, Quackenbush J: A concise guide to CDNA microarray analysis. Biotechniques 2000, 29:548-4. 556.

9. Marguerat S, Bahler J: RNA-seq: from technology to biology. Cell Mol Life Sci 2010, 67:569-579.

10. Nagalakshmi U, Wang Z, Waern K, Shou C, Raha D, Gerstein M, Snyder M: The transcriptional landscape of the yeast genome defined by RNA sequencing. Science 2008, 320:1344-1349.

11. Nagalakshmi U, Waern K, Snyder M: RNA-Seq: a method for comprehensive transcriptome analysis. Curr Protoc Mol Biol 2010, Chapter 4:. Unit 4.11.1-13.

12. Ramsay G: DNA chips: state-of-the art. Nat Biotechnol 1998, 16:40-44

13. Schena M, Shalon D, Davis RW, Brown PO: Quantitative monitoring of gene expression patterns with a complementary DNA microarray. Science 1995, 270:467-470.
14. Tan PK, Downey TJ, Spitznagel EL Jr, Xu P, Fu D, Dimitrov DS, Lempicki RA, Raaka BM, Cam MC: Evaluation of gene expression measurements from commercial microarray platforms. Nucleic Acids Res 2003, 31:5676-5684.

15. Toung JM, Morley M, Li M, Cheung VG: RNA-sequence analysis of human B-cells. Genome Res 2011, 21:991-998.

16. Wilhelm BT, Marguerat S, Watt S, Schubert F, Wood V, Goodhead I, Penkett CJ, Rogers J, Bahler J: Dynamic repertoire of a eukaryotic transcriptome surveyed at single-nucleotide resolution. Nature 2008, 453:1239-1243.

17. Xiang CC, Chen Y: cDNA microarray technology and its applications. Biotechnol Adv 2000, 18:35-46.

18. Mortazavi A, Williams BA, McCue K, Schaeffer L, Wold B: Mapping and quantifying mammalian transcriptomes by RNA-Seq. Nat Methods 2008, 5:621-628.

19. Pariset L, Chillemi G, Bongiorni S, Romano SV, Valentini A: Microarrays and high-throughput transcriptomic analysis in species with incomplete availability of genomic sequences. N Biotechnol 2009, 25:272-279.

20. Schena M, Heller RA, Theriault TP, Konrad K, Lachenmeier E, Davis RW: Microarrays: biotechnology's discovery platform for functional genomics. Trends Biotechnol 1998, 16:301-306.

21. Fu X, Fu N, Guo S, Yan Z, Xu Y, Hu H, Menzel C, Chen W, Li Y, Zeng R, et al: Estimating accuracy of RNA-Seq and microarrays with proteomics. BMC Genomics 2009, 10:161.

22. Shendure J: The beginning of the end for microarrays? Nat Methods 2008, 5:585-587.

23. van Vliet $\mathrm{AH}$ : Next generation sequencing of microbial transcriptomes: challenges and opportunities. FEMS Microbiol Lett 2010, 302:1-7.

24. Raz T, Kapranov P, Lipson D, Letovsky S, Milos PM, Thompson JF: Protocol dependence of sequencing-based gene expression measurements. PLoS One 2011, 6:e19287.

25. Martin JA, Wang Z: Next-generation transcriptome assembly. Nat Rev Genet 2011, 12:671-682.

26. Zhou X, Ren L, Meng Q, Li Y, Yu Y, Yu J: The next-generation sequencing technology and application. Protein Cell 2010, 1:520-536.

27. 't Hoen PA, Ariyurek $Y$, Thygesen HH, Vreugdenhil E, Vossen RH, de Menezes RX, Boer JM, van Ommen GJ, den Dunnen JT: Deep sequencing-based expression analysis shows major advances in robustness, resolution and inter-lab portability over five microarray platforms. Nucleic Acids Res 2008, 36:e141. doi:e141.

28. Leimena MM, Wels M, Bongers RS, Smid EJ, Zoetendal EG, Kleerebezem M: Comparative Analysis of Lactobacillus plantarum WCFS1 Transcriptomes by Using DNA Microarray and Next-Generation Sequencing Technologies. Appl Environ Microbiol 2012, 78:4141-4148.

29. Marioni JC, Mason CE, Mane SM, Stephens M, Gilad Y: RNA-seq: an assessment of technical reproducibility and comparison with gene expression arrays. Genome Res 2008, 18:1509-1517.

30. Su Z, Li Z, Chen T, Li QZ, Fang H, Ding D, Ge W, Ning B, Hong H, Perkins $R G$, et al: Comparing next-generation sequencing and microarray technologies in a toxicological study of the effects of aristolochic acid on rat kidneys. Chem Res Toxicol 2011, 24:1486-1493.

31. Wengelnik K, Bonas U: HrpXV, an AraC-type regulator, activates expression of five of the six loci in the hrp cluster of Xanthomonas campestris pv. vesicatoria. J Bacteriol 1996, 178:3462-3469.

32. da Silva AC, Ferro JA, Reinach FC, Farah CS, Furlan LR, Quaggio RB, Monteiro-Vitorello CB, Van Sluys MA, Almeida NF, Alves LM, et al: Comparison of the genomes of two Xanthomonas pathogens with differing host specificities. Nature 2002, 417:459-463.

33. Guo Y, Figueiredo F, Jones J, Wang N: HrpG and HrpX play global roles in coordinating different virulence traits of Xanthomonas axonopodis pv. citri. Mol Plant Microbe Interact 2011, 24:649-661.

34. Civerolo E: Bacterial canker disease of citrus. J Rio Grande Vall Hortic Soc 1984, 37:127-145.

35. Astua-Monge G, Freitas-Astua J, Bacocina G, Roncoletta J, Carvalho SA, Mchado MA: Expression profiling of virulence and pathogenicity genes of Xanthomonas axonopodis pv. citri. J Bacteriol 2005, 187:1201-1205.

36. Fenselau S, Bonas $\mathrm{U}$ : Sequence and expression analysis of the hrpB pathogenicity operon of Xanthomonas campestris pv. vesicatoria which encodes eight proteins with similarity to components of the Hrp, Ysc, Spa, and Fli secretion systems. Mol Plant Microbe Interact 1995, 8:845-854

37. Koebnik R, Kruger A, Thieme F, Urban A, Bonas U: Specific binding of the Xanthomonas campestris pv. vesicatoria AraC-type transcriptional 
activator HrpX to plant-inducible promoter boxes. J Bacterio/ 2006, 188:7652-7660.

38. Noel L, Thieme F, Nennstiel D, Bonas U: Two novel type III-secreted proteins of Xanthomonas campestris pv. vesicatoria are encoded within the hrp pathogenicity island. J Bacteriol 2002, 184:1340-1348.

39. Alfano JR, Collmer A: The type III (Hrp) secretion pathway of plant pathogenic bacteria: trafficking harpins, Avr proteins, and death. J Bacteriol 1997, 179:5655-5662.

40. Bonas U: hrp genes of phytopathogenic bacteria. Curr Top Microbiol Immunol 1994, 192:79-98.

41. Buttner D, Bonas U: Regulation and secretion of Xanthomonas virulence factors. FEMS Microbiol Rev 2010, 34:107-133.

42. Iwamoto M, Oku T: Cloning and molecular characterization of hrpX from Xanthomonas axonopodis pv. citri. DNA Seq 2000, 11:167-173.

43. Gurlebeck D, Thieme F, Bonas U: Type III effector proteins from the plant pathogen Xanthomonas and their role in the interaction with the host plant. J Plant Physiol 2006, 163:233-255.

44. Oku T, Alvarez AM, Kado Cl: Conservation of the hypersensitivitypathogenicity regulatory gene hrpX of Xanthomonas campestris and $\mathrm{X}$ oryzae. DNA Seq 1995, 5:245-249

45. Lahaye $\mathrm{T}$, Bonas $\mathrm{U}$ : Molecular secrets of bacterial type III effector proteins. Trends Plant Sci 2001, 6:479-485.

46. Kelley DR, Schatz MC, Salzberg SL: Quake: quality-aware detection and correction of sequencing errors. Genome Biol 2010, 11:R116.

47. Klebanov $L$, Yakovlev A: How high is the level of technical noise in microarray data? Biol Direct 2007, 2:9.

48. Oshlack A, Wakefield MJ: Transcript length bias in RNA-seq data confounds systems biology. Biol Direct 2009, 4:14.

49. Sahl JW, Rasko DA: Analysis of global transcriptional profiles of enterotoxigenic Escherichia coli isolate E24377A. Infect Immun 2012, 80:1232-1242

50. Alfano JR, Collmer A: Type III secretion system effector proteins: double agents in bacterial disease and plant defense. Annu Rev Phytopathol 2004 , 42:385-414

51. Collmer A, Bauer DW: Erwinia chrysanthemi and Pseudomonas syringae: plant pathogens trafficking in extracellular virulence proteins. Curr Top Microbiol Immunol 1994, 192:43-78.

52. Cornelis GR: The type III secretion injectisome. Nat Rev Microbiol 2006 , 4:811-825.

53. Szczesny R, Jordan M, Schramm C, Schulz S, Cogez V, Bonas U, Buttner D: Functional characterization of the Xcs and Xps type II secretion systems from the plant pathogenic bacterium Xanthomonas campestris pv vesicatoria. New Phytol 2010, 187:983-1002.

54. Van GF, Genin S, Boucher C: Conservation of secretion pathways for pathogenicity determinants of plant and animal bacteria. Trends Microbiol 1993, 1:175-180

55. White FF, Potnis N, Jones JB, Koebnik R: The type III effectors of Xanthomonas. Mol Plant Pathol 2009, 10:749-766.

56. Lindgren PB: The role of hrp genes during plant-bacterial interactions. Annu Rev Phytopathol 1997, 35:129-152.

57. Lipscomb L, Schell MA: Elucidation of the regulon and cis-acting regulatory element of $\mathrm{HrpB}$, the AraC-type regulator of a plant pathogen-like type III secretion system in Burkholderia pseudomallei. J Bacteriol 2011, 193:1991-2001.

58. Kim JG, Park BK, Yoo CH, Jeon E, Oh J, Hwang I: Characterization of the Xanthomonas axonopodis pv. glycines Hrp pathogenicity island. J Bacteriol 2003, 185:3155-3166.

59. Hu GB, Rice WJ, Drose S, Altendorf K, Stokes DL: Three-dimensional structure of the KdpFABC complex of Escherichia coli by electron tomography of two-dimensional crystals. J Struct Biol 2008, 161:411-418.

60. Jehl MA, Arnold R, Rattei T: Effective-a database of predicted secreted bacterial proteins. Nucleic Acids Res 2011, 39:D591-D595.

61. Korotkov KV, Sandkvist M, Hol WG: The type II secretion system: biogenesis, molecular architecture and mechanism. Nat Rev Microbiol 2012, 10:336-351.

62. Furutani A, Takaoka M, Sanada H, Noguchi Y, Oku T, Tsuno K, Ochiai H, Tsuge S: Identification of novel type III secretion effectors in Xanthomonas oryzae pv. oryzae. Mol Plant Microbe Interact 2009, 22:96-106.

63. Wang $L$, Rong W, He C: Two Xanthomonas extracellular polygalacturonases, PghAxc and PghBxc, are regulated by type III secretion regulators $\mathrm{HrpX}$ and $\mathrm{HrpG}$ and are required for virulence. $\mathrm{Mol}$ Plant Microbe Interact 2008, 21:555-563.

64. Mukherjee K, Burglin TR: MEKHLA, a novel domain with similarity to PAS domains, is fused to plant homeodomain-leucine zipper III proteins. Plant Physiol 2006, 140:1142-1150.

65. Ashburner M, Ball CA, Blake JA, Botstein D, Butler H, Cherry JM, Davis AP, Dolinski K, et al: Gene ontology: tool for the unification of biology The Gene Ontology Consortium. Nat Genet 2000, 25:25-29.

66. Kanehisa M, Goto S, Kawashima S, Nakaya A: The KEGG databases at GenomeNet. Nucleic Acids Res 2002, 30:42-46.

67. Caspi R, Altman T, Dreher K, Fulcher CA, Subhraveti P, Keseler IM, Kothari A Krummenacker $\mathrm{M}$, et al: The MetaCyc database of metabolic pathways and enzymes and the BioCyc collection of pathway/genome databases. Nucleic Acids Res 2012, 40:D742-D753.

68. Carninci P, Kasukawa T, Katayama S, Gough J, Frith MC, Maeda N, Oyama R, Ravasi $T$, Lenhard $B$, Wells $C$, et al: The transcriptional landscape of the mammalian genome. Science 2005, 309:1559-1563.

69. Graveley BR, Brooks AN, Carlson JW, Duff MO, Landolin JM, Yang L, Artieri CG, van Baren MJ, Boley N, Booth BW, et al: The developmental transcriptome of Drosophila melanogaster. Nature 2011, 471:473-479.

70. Mane SP, Evans C, Cooper KL, Crasta OR, Folkerts O, Hutchison SK, Harkins $\Pi$, Thierry-Mieg D, Thierry-Mieg J, Jensen RV: Transcriptome sequencing of the Microarray Quality Control (MAQC) RNA reference samples using next generation sequencing. BMC Genomics 2009, 10:264.

71. Pan Q, Shai O, Lee LJ, Frey BJ, Blencowe BJ: Deep surveying of alternative splicing complexity in the human transcriptome by high-throughput sequencing. Nat Genet 2008, 40:1413-1415.

72. Sultan M, Schulz MH, Richard H, Magen A, Klingenhoff A, Scherf M, Seifert M, Borodina T, Soldatov A, Parkhomchuk D, et al: A global view of gene activity and alternative splicing by deep sequencing of the human transcriptome. Science 2008, 321:956-960

73. Trapnell C, Williams BA, Pertea G, Mortazavi A, Kwan G, van Baren MJ, Salzberg SL, Wold BJ, Pachter L: Transcript assembly and quantification by RNA-Seq reveals unannotated transcripts and isoform switching during cell differentiation. Nat Biotechnol 2010, 28:511-515.

74. Van BH, Nislow C, Blencowe BJ, Hughes TR: Most "dark matter" transcripts are associated with known genes. PLoS Biol 2010, 8:e1000371.

75. Bullard $\mathrm{H}$, Purdom E, Hansen KD, Dudoit S: Evaluation of statistical methods for normalization and differential expression in mRNA-Seq experiments. BMC Bioinforma 2010, 11:94.

76. Labaj PP, Leparc GG, Linggi BE, Markillie LM, Wiley HS, Kreil DP: Characterization and improvement of RNA-Seq precision in quantitative transcript expression profiling. Bioinformatics 2011, 27:i383-i391.

77. Risso D, Schwartz K, Sherlock G, Dudoit S: GC-content normalization for RNA-Seq data. BMC Bioinforma 2011, 12:480

78. Draghici S, Khatri P, Eklund AC, Szallasi Z: Reliability and reproducibility issues in DNA microarray measurements. Trends Genet 2006, 22:101-109

79. Goryachev AB, Macgregor PF, Edwards AM: Unfolding of microarray data. J Comput Biol 2001, 8:443-461.

80. Kerr MK, Martin M, Churchill GA: Analysis of variance for gene expression microarray data. J Comput Biol 2000, 7:819-837.

81. Tseng GC, Oh MK, Rohlin L, Liao JC, Wong WH: Issues in CDNA microarray analysis: quality filtering, channel normalization, models of variations and assessment of gene effects. Nucleic Acids Res 2001, 29:2549-2557.

82. Wang $X$, Wang D, Chen X, Hu M, Wang J, Li Y, Guo N, Shen B: cDNA cloning and function analysis of two novel erythroid differentiation related genes. Sci China C Life Sci 2001, 44:99-105

83. Cleveland WS, Devlin SJ, Grosse E: Regression by Local Fitting: Methods, Properties, and Computational Algorithms. J Econ 1988, 37:87-114

84. Engelen $\mathrm{K}$, Coessens B, Marchal K, De MB: MARAN: normalizing micro-array data. Bioinformatics 2003, 19:893-894.

85. Ihaka R, Gentleman R: R: A language for data analysis and graphics. Journal of Computational and Graphical Statistics. Journal of Computational and Graphical Statistics 1996, 5:299-314.

86. Venet D: MatArray: a Matlab toolbox for microarray data. Bioinformatics 2003, 19:659-660.

87. Kumar R, Lawrence ML, Watt J, Cooksey AM, Burgess SC, Nanduri B: RNA-seq based transcriptional map of bovine respiratory disease pathogen "Histophilus somni 2336". PLoS One 2012, 7:e29435. 
88. Wurtzel O, Sapra R, Chen F, Zhu Y, Simmons BA, Sorek R: A single-base resolution map of an archaeal transcriptome. Genome Res 2010, 20:133-141

89. Yoder-Himes DR, Chain PS, Zhu Y, Wurtzel O, Rubin EM, Tiedje JM, Sorek R: Mapping the Burkholderia cenocepacia niche response via highthroughput sequencing. Proc Natl Acad Sci U S A 2009, 106:3976-3981.

90. Tarazona S, Garcia-Alcalde F, Dopazo J, Ferrer A, Conesa A: Differential expression in RNA-seq: a matter of depth. Genome Res 2011, 21:2213-2223.

91. Daniels MJ, Barber CE, Turner PC, Sawczyc MK, Byrde RJ, Fielding AH: Cloning of genes involved in pathogenicity of Xanthomonas campestris pv. campestris using the broad host range cosmid pLAFR1. EMBO J 1984, 3:3323-3328.

92. Anders $\mathrm{S}$, Huber W: Differential expression analysis for sequence count data. Genome Biol 2010, 11:R106.

93. Reimers M, Carey VJ: Bioconductor: an open source framework for bioinformatics and computational biology. Methods Enzymol 2006, 411:119-134.

94. Altschul SF, Madden TL, Schaffer AA, Zhang J, Zhang Z, Miller W, Lipman DJ: Gapped BLAST and PSI-BLAST: a new generation of protein database search programs. Nucleic Acids Res 1997, 25:3389-3402.

95. Bindea G, Mlecnik B, Hackl H, Charoentong P, Tosolini M, Kirilovsky A, Fridman WH, Pagès F, Trajanoski Z, Galon J: ClueGO: a Cytoscape plug-in to decipher functionally grouped gene ontology and pathway annotation networks. Bioinformatics 2009, 25:1091-1093.

96. Shannon P, Markiel A, Ozier O, Baliga NS, Wang JT, Ramage D, Amin N, Schwikowski B, Ideker T: Cytoscape: a software environment for integrated models of biomolecular interaction networks. Genome Res 2003, 13:2498-2504.

97. Livak KJ, Schmittgen TD: Analysis of relative gene expression data using real-time quantitative PCR and the 2(-Delta Delta C(T)) Method. Methods 2001, 25:402-408.

\section{doi:10.1186/1471-2164-13-629}

Cite this article as: Kogenaru et al:: RNA-seq and microarray complement each other in transcriptome profiling. BMC Genomics 2012 13:629.

\section{Submit your next manuscript to BioMed Central and take full advantage of:}

- Convenient online submission

- Thorough peer review

- No space constraints or color figure charges

- Immediate publication on acceptance

- Inclusion in PubMed, CAS, Scopus and Google Scholar

- Research which is freely available for redistribution 